\title{
O que passou?
}

\section{Adriana Grosman}

\begin{abstract}
Resumo
Este texto é o resultado da escrita de uma passagem, feita de tantos passos que foram dados até a decisão do olhar/saber, do fim de uma análise e outros mais até o dizer/saber do passe, exame do que faz um analisante decidir colocar-se como analista, este que, como profere Lacan, "só se autoriza de si mesmo" no seu tempo. Ele foi escrito, num primeiro momento, para ser falado, de forma que é um texto que não perde essa característica de um relato da passagem, causada pela surpresa da nomeação e da experiência do fim de análise e do que isso pode representar. Portanto, fim de um lado e abertura de outro, iniciada por essa primeira fala, agora publicada, depois de um caminho já avançado de outras falas.
\end{abstract}

\section{Palavras-chave:}

Passe; Final de análise; Experiência; Passagem.

\section{What has passed?}

\begin{abstract}
This text is the result of the writing of a passage made of so many steps that were taken until the decision to look/know, from the end of an analysis and other ends until the say/know of the pass, examination of what makes an analysand decide to put himself as an analyst, he who, as Lacan says, "only authorizes himself" in his time. This was written primarily to be spoken, so it is a text that does not lose this characteristic of a passage account, caused by the surprise of the appointment and the experience of the end of analysis and what it may represent. Therefore, end on one side and opening on the other, started by this first speech, now published, after an already advanced path of other speeches.
\end{abstract}

\section{Keywords:}

Pass; End of analysis; Experience; Passage. 


\section{¿Qué ha pasado?}

\section{Resumen}

Este texto es el resultado de escribir un pasaje, hecho de tantos pasos que se tomaron hasta la decisión de mirar/saber, desde el final de un análisis y otros hasta el decir/saber del pase, el examen de lo que hace que un analizante decida hacerse analista, aquello que, como dice Lacan, "solo se autoriza" en su tiempo. Eso se escribió en primer lugar para ser hablado, por lo que es un texto que no pierde esa característica de un recuento de pasajes, causado por la sorpresa de nombrar y la experiencia del final del análisis, y lo que eso puede representar. Así, fin por un lado y apertura por el otro, iniciada por este primer discurso, ahora publicado, después de un camino ya avanzado de otras charlas.

\section{Palabras clave:}

Pase; Análisis final; Experiencia; Pasaje.

\section{Que s'est-il passé?}

\section{Résumé}

Ce texte est le résultat de l'écriture d'un passage, constitué de tant de pas qui ont été faits jusqu'à la décision de regarder/savoir, de la fin d'une analyse au dire/ savoir de la passe, l'examen de ce qui pousse un analysant à décider de se poser en tant qu'analyste, celui qui, comme le dit Lacan, « ne s'autorise que de soi ». Ce texte a d'abord été écrit pour être dit, il s'agit donc d'un texte qui ne perd pas cette caractéristique de récit d'un passage déclenché par la surprise de la nomination et de l'expérience de la fin d'analyse et de ce qu'elle peut représenter. D’un côté la fin, et d'autre l'ouverture démarrée par cette première intervention, désormais publiée, après un chemin déjà parcouru par d'autres interventions.

\section{Mots-clés :}

Passe ; Fin d'analyse ; Expérience ; Passage. 
Um passo, uma passagem, maneira de andar, andamento, ato de deslocar o apoio de um pé a outro enquanto se anda, mas também o espaço compreendido em cada um desses deslocamentos. Mesmo assim, eles não são iguais e causam, muitas vezes, intranquilidade, desequilíbrio, tontura, perturbação, vertigem. Nem todos os andamentos passam por isso, mas no passe passa. Pode seguir-se andando para sempre, não sem sintoma, inibição e angústia; pode-se, no entanto, seguir andando para sempre sem parar ou esbarrar num fim.

Só se sabe dele, do fim, a partir da experiência, da decisão singular que passa por entre esses passos, de um a outro, ou do Outro ao Um, e, a partir daí, o Passe que, como num passa-anel, passa-se ora o anel, ora nada, tentando saber do anel escondido; Um, na contingência da brincadeira, fica com ele, e este, depois de quieto, oferece seu saber e recomeça a brincadeira. Passa-se para o outro, outros. Já com a experiência do um, repete e renova essa experiência, se assim lhe for possível.

O jogo continua, mas "só se pode estar nele por tê-lo demandado de fato, senão formalmente", diz Lacan (1967/2003, p. 249) na "Proposição"; suposição do sujeito, do querer dizer, enfrentar a verdade, pois a verdade falta: "Só temos a escolha entre enfrentar a verdade ou ridicularizar nosso saber" (Lacan, 1967/2003, p. 258). Esse é o momento de saber do fim. Tantos passos dados até a decisão do olhar-saber, e outros mais até o dizer-saber do passe, exame do que faz um analisante decidir colocar-se como analista, este que, como profere Lacan, "só se autoriza de si mesmo" no seu tempo.

Dessa forma, como dizer dos passos incertos do sujeito até que atravesse as confabulações mais ricas e encobridoras e, por que não, enganadoras do Real? Deste que não sabe nada além do já sabido e do ponto aonde chegar, mas faz apostas para os passos.

No início, um não querer saber, protegido por uma inibição... Até diante da notícia - "Você foi nomeada", um surpreendente passo para trás - "Eu não, não pode ser". Ao que escuto - "Você pediu, lembra?".

Lembro, e lembro até o ponto onde as elucubrações foram barradas e caminhei diferentemente, criando novos passos, ponto a ponto, fazendo laços, novos laços. Estes, antes, eram inimagináveis, porque, antes do impossível de ser visto, a demanda do outro não cansa de não cessar de não se escrever e de ocupar, ocupar demais, falseando um lugar de onde sempre não se espera outra coisa que não restos.

Talvez estragos - afinal, por que não? Da forma como somos feitos, nós, da espécie humana, estragos são o que pode nos acontecer de melhor.

Um desencontro do que o sujeito espera encontrar para o que encontra, de que só vai se dar conta quando procura uma análise. Na certeza do encontro esperado com sua fantasia e sua visada fálica, a análise introduz a contingência de um encontro com o real. 
Incidentes, ou verdadeiros golpes narcísicos, acontecem. Diante dos acidentes, como a perna quebrada do meu filho, a dor era grande, e talvez maior, porque aí se abria alguma fresta de real, descortinando-se a fantasia, e a contingência é contada; diante dela não dá para recuar. A caída do Outro faz mesmo enxergar esse monte impossível do Real à frente. Não queria saber disso, já vivendo a dor da quebrada de perna da fantasia, golpe fatal do visto entre as frestas, que se apresentava trazendo muito medo.

\section{O que passou, então?}

Uma surpresa e Um horror, se for possível resumir assim a quantidade de afetos que povoam uma análise. Começo pela surpresa, desde o começo até o fim, e talvez mais no fim, uma palavra que diz d'isso, surpresa do fim, de saber do fim, de não saber. Surpresa causada pela análise, pelos passos dados, pelo novo sujeito do fim, pelo dispositivo, pela contingência, pela fala dirigida ao passador, pelo encontro com os passadores, com a notícia de que algo passou.

E, mais ainda, a partir de cada novo encontro com essa nova função, nova aposta, suponho. Encontros com o limite do saber, do inconsciente, de Deus e da mulher, como articula Lacan, e mais ainda ninguém sabe. A inconsistência do Outro bate à minha porta, a cada vez me lembrando de uma singularidade recém-desenhada, assim como um pacientezinho que insiste em bater forte na minha porta quando chega, não interessa se cedo ou tarde - “cheguei!", diz com a batida. E, a cada nova chegada sua, eu estremecia, se sabia. Não sabia, não.

Essa é talvez a forma mais banal de descrever esse encontro com o real numa análise, e, por aí, posso falar de um ponto diferente que me interroguei desde quando acreditava que havia um ponto a chegar, especialmente para ser uma "boa” analista. Não há um caminho certo, muito menos linear.

O que me intrigava era a minha escuta afiada na clínica; para ouvir o outro, temos de nos desfazer de muitos conceitos e saberes para certa soltura, que percebia aí e em nenhum outro lugar. Essa interrogação se repetiu ao longo de todo o meu percurso de análise. No final, a clínica mudou, permitia outra posição em relação àquele que falava de sua dor.

Assim, fascinada, é como eu ficava em vários momentos, especialmente quando percebia que o mais sofrido do paciente poderia ser uma perda importante, uma traição ou até um olho que não era azul ou, mesmo, um jogo perdido. Não havia uma medida certa para essa dor do outro, não que possamos conhecer. Não importava de qual Um se tratava, era único. Em seguida, identifiquei isso com o que mais admirava na analista, até então algo desconhecido para mim.

E o Horror, pois bem, nada simples encará-lo; desvelamento do real, esse opositor da realidade, essa realidade com a qual nos conformamos até que reparamos 
no dizer, escape, aquilo que retorna e não cessa de não ser dito, talvez encontro com a verdade, como diz brilhantemente Colette Soler (2005, p. 78): "a verdade não é triste, é horrível, desumana; e o horror não deprime, mas antes, desperta". Despertada pelo horror.

\section{Uma fotografia, não qualquer uma}

Fui fotografada, fui pega, isso revelava o incômodo com o olhar do outro. Lacan, no Seminário XI, diz:

(...) o que determina fundamentalmente no visível é o olhar que está do lado de fora. É pelo olhar que entro na luz, e é do olhar que recebo seu efeito. Donde se tira que o olhar é o instrumento pelo qual a luz se encarna, e pelo qual - se vocês me permitirem servir-me de um termo, como faço frequentemente, decompondo-o — sou fotografado. (Lacan, 1964/1998, p. 104)

Com a foto, imagem, lembrava o momento em que fui fotografada, jogando areia naquele que me fotografava, brava; lembro o flagra do olhar. Mostrava, guardava, registrava o que não podia ser visto... indignação com o outro.

Interessante que, mais uma vez, a cena era tão para ser esquecida que dava raiva ao ser contada e resgatada pela analista como aquilo que aparecia e não poderia aparecer. Engomada pelo olhar do outro, só aparecia por relances e era resgatada pela analista. Odiava ser fotografada, odiava lembrar essa foto, a querida dos avós que corria das fotos, jogava areia. Em alguns momentos, estranhava essa braveza toda, não combinava.

Duas versões de Adriana: uma completamente resistida, apontada pela analista, mas quase não vista, que jogava areia. Estranhada no início e, mais ainda, evitada, enquanto a outra, iluminada pelos raios da fantasia, aparecia, logo apelidada de engomada; tratava-se da primeira filha, primeira neta, primeira sobrinha, que deixava tios e avós literalmente de quatro atrás dela. Para a avó paterna, uma menininha, após três filhos homens, era tudo o que desejava. Evitava, dessa forma, saber do estranho, completamente alienada no desejo do outro, qualquer cisco faria um risco, desfazia-se, assim, dessa parte obscura, do que não fazia sentido.

Essa imagem, que já não compunha a imagem toda da engomada, ou a dividia, não cabia, simplesmente. Desse modo, tal cena era inicialmente interpretada como maldade do outro, dos avós no caso, que também não combinava. Aos poucos, a imagem-fotografia se duplicava em análise, e assim a divisão aparecia. Como notar a ausência? Estamos sempre encobrindo o furo.

Podia ver quem me olhava, me olhando, mas não entendia o ódio que isso causava, insistia em ter de me conformar ao olhar, este que recebia; por outro lado, 
que rebeldia poderia ser aquela? Talvez primeiro abalo da figura "toda engomada", a partir do estranhamento.

A presença do analista nesse momento, não olhando, testemunho da perda, apresenta um intervalo que aponta para a posição do inconsciente. Uma presença diferente, como uma causa perdida, como o objeto perdido de nosso gozo, que está justamente no intervalo do que não pode ser visto. Faz aparecer, assim, as marcas dessa falha.

No início, alguma resistência - não sei se é possível sem ela —, mas retornava após a experiência de outra longa análise de onde saí "barrada no baile" — e só descobri isso tardiamente, é claro. A vivência de um analista presente "de fato", e não testemunho da perda, me fez interromper essa análise, sem que eu tivesse a menor ideia disso antes dessa nova experiência.

Nova experiência onde revivi a separação de um casamento de nove anos, seguida de uma paixão. Paixão que apareceu no momento da separação e com ela um corpo desejante. A ideia do encontro “Todo" preenchia e enfeitiçava, um afeto jamais sentido transbordava, e a história costurava e escrevia tudo que poderia acontecer de melhor, até que um golpe provocou a separação, que não era possível. Muito sofrida, portanto. Não era qualquer perda. Cada novo giro era medido e revivido pela dor daquele momento, lembrado agora.

Por que acabava aquilo que era para sempre? Essa perda, esse objeto, o cara desciam rasgando e, pior, trouxeram a imagem da apagada, engomada, já que combinava com muitas outras posições, medo de se expor, de aparecer, de ser. A imagem lembrada dizia muito, dava raiva quando se via, aquela que enaltecia o outro, que acreditou ter encontrado o tal, e a conta parecia fechar, não faltar.

A partir daí, foram precisos passos duros e largos para encontrar outros, "outrinhos", já que a primeira paixão a gente nunca esquece, deixa marcas e lembra até o amor materno, e, daí, outros. Um engano e identificações que fazem função, já que têm a força para combater ou pensar esse enlaçamento pelo olhar, que cuidava para não "desengomar" ao olhar do outro: A mãe.

Descubro, assim, que o que parecia ser a primeira escolha, primeiro marido, era para manter o mesmo, tudo como estava. Continuar filha, mulher, não. Mas mãe, sim; tive duas filhas gêmeas desse casamento, que muito me ensinaram e muito me ocuparam. Nasceram prematuras, e a entrega foi grande, até se fortalecerem, o medo de perdê-las também, o corpo falava, eu não, mas agia mesmo assim, me sentia potente com as duas nos braços, que logo cresceram.

Outra caída foi a do homem de fardas, não existia! O homem potente, meu pai. Machado de Assis ajudou com essa imagem, no conto chamado "O espelho - esboço de uma nova teoria da alma humana”, e é brilhante. Cito-o: 
Não há uma só alma, há duas (...) Nada menos de duas almas (...) uma que olha de dentro para fora, outra que olha de fora para dentro... (...) A alma exterior pode ser um espírito, um fluido, um homem, muitos homens, um objeto, uma operação (...). (Assis, 2008, p. 339)

"Nomeado alferes da guarda nacional”, causa na família verdadeira comoção. "Ao tempo em que a consciência do homem se obliterava, a do alferes tornava-se viva e intensa (...) no fim de três semanas, era outro, totalmente alferes" (Assis, 2008, p. 339).

Operação da alma. O espelho e a imagem ajudam nessa operação. Com a farda, todos os nomes eram apenas um, tanto fazia. O singular e o próprio não existiam. E me separar dessa imagem, da farda, virou uma emergência, que começou a ser vista quando me separei pela primeira vez.

Tive que "me mexer" muito para achar outros, pequenos outros "des-importantes", e deu muito trabalho até conseguir "brincar com os homens", momento de rompimento da análise antiga, que só pude rever nesta. Aquele analista parecia querer "orientar-me"... Essa nova analista caminhava em outro sentido, o da "desorientação", para não falar (de)formação, como descobri bem depois.

Com algumas quedas, sobra alguém, uma que sempre esteve ali, uma mãe, mulher impecável, que do salto se sustentava não só no meu olhar. Toda eu era para continuar fisgando o seu desejo; lembro outra imagem, outra fotografia emblemática "da menininha no trocador", uma menina, boneca sentada com um vestido branco engomado, imóvel, numa fotografia? Posso dizer que sim, imóvel, imaculável e responsável pelo apelido de engomada.

Nas entrelinhas da fala da engomada, a analista apontava para aquilo que não combinava na cena, dirigindo o meu olhar para a fresta, falha, daquilo que não podia ser visto, que logo buscava o olhar do outro como forma de estancar a ferida, angústia, desde a primeira vista.

Tentava me encobrir, imitar, fazer e não aparecer, esse não querer saber que me custou, nessa difícil travessia, mas que acertava no sentido de deixar a engomada ainda mais impecável, alimentando esse gozo, esse brilho. Tinha um brilho, talvez por isso risco.

Nas brincadeiras com os homens, sedução e potência podiam aparecer, um pouco! E nesse momento entra um que diz: "Por que não namorar sério e por que não parar aí?”. Ao topar com isso, ou esse, parecia ter escolhido o exercício certo para trabalhar o tônus necessário para fortalecer, justamente, o que me era mais frágil, o posicionamento. Muita briga foi necessária.

Porque aguento o que aguento, abre frestas para pensar o outro. Frestas no outro, frestas na mãe, coisas escondidas e não sabidas do outro que estavam lá, abalo 
no desejo da mãe, não mais intocável. Por outro lado, que solidão suspeitar não ter ou nunca ter tido esse outro nesse lugar especial e todo.

O Outro foi sendo desmascarado; no mestrado, a angústia para escrever me parava e trazia, novamente, a questão de como ser olhada. O que a minha escrita transmite e pode revelar de mim? Passa pelo escondido o desejo de ser olhada e se virar com essa angústia, de se ver retida por aquele olhar, procurar mais disso, procurar o aval do mestre e se separar disso.

Certa tristeza, quem sobrará? Certa briga, que sem graça, isso! Como seriam as relações dali em diante se não sobrar ninguém... Fico brava com o caminho da análise. Já vislumbrava, aí, aonde poderia chegar?

Casada novamente, mas diante de um novo vazio: minhas filhas, já grandes, decidem ir juntas estudar fora, fazer intercâmbio. E vínhamos brincando de ter outro filho, a brincadeira avançou, e a gravidez foi um ato que trouxe, com ele, a ideia de acontecimento, angústia, imprevisto, real.

Perturbou meu sono sustentar esse ato. Foi o início de muito medo.

Alegria e medo!

Muitas ideias vinham caindo, e a fantasia já abalada trazia a sensação, que insistia, de queda livre. Escrevi um texto - "De um pânico ao outro" - tratando da impossibilidade da separação vivida como pânico de uma paciente ao meu próprio, chamado de desencosto do outro. Queda livre. Quando acharia conforto? No encosto, não há.

Outra surpresa: quando me preparava para me tornar membro do Fórum SP, recebo a ligação e o convite para ser passadora. Que loucura era aquela, e, ainda, endossada pela analista! Ouvir de outro a análise que chegou ao fim - Que fim?!... - , quando eu não queria saber disso. Desde o real, eu também não queria saber disso... ainda.

Mesmo assim, topo, curiosa.

Escuto o outro e, com isso, a dor do aprisionamento da fantasia que amarra o sujeito, por mais diferente da engomada que o outro possa ser. Era possível tanta dor "igual" para sair de lugares tão diferentes? Diferença lacaniana fundamental, não há suficiência nesse momento que faça a saída mais fácil: o enlace com o outro, fortalecido pela fantasia, dói enquanto dura, à sua maneira, mais ou menos como a passagem (pessach/passo), no caso dos judeus, representada pela travessia do Mar Vermelho, “es decir el PASO”, da escravatura à liberdade. Não há atravessamento fácil.

Uma travessia libertadora e dura.

Separar-se daquilo que pareceu ser nem bom, nem mal, já que predicá-lo seria uma tentativa de significar o impossível, como diz Lacan (1972-1973/2010, p. 67) no Seminário $X X$ : "essa dimensão imaginativa, é justamente nisso que nos alimentamos". 
O vazio dá muito medo: como interpretar o que acontecia com esse corpo, com manifestações estranhas, corpos estranhos no próprio corpo, medo de ficar doente, ter câncer, um corpo aparecendo demais? De alguma forma, o corpo é criado a partir de uma imagem, cuidada para que não aparecesse, até agora. Como tomar posse desse corpo ex-sistente, estranho, que aparecia?

Falar onde essas coisas, senão na análise? Então, como seria um fim? Impossível. Tenho, assim, um sonho (de horror): num ambiente de hospital e exames, uma coisa visceral, uma coisa no corpo, em dois pontos, no pescoço e em algum lugar embaixo. Porém, ao mesmo tempo que ia morrer, as coisas aconteciam, a vida estava rolando, o esquisito era isso.

Parecia dizer de uma separação em jogo, horror e vida, vida e morte (perda), antes contraditórios, impossíveis de conviver. O sonho traz essa lógica esquisita, isso como possível. E logo uma associação do hospital e exames com injeção, significante importante da infância, porque sempre trouxe muito medo, e um "escondido" dos avós maternos muito presentes; especialmente quando meus pais viajavam.

A cena que se repetia era que, enquanto eles estavam cuidando da gente, se alguém ficava doente, não diziam que o médico ou o farmacêutico viriam para dar injeção em nós (eu e minhas duas irmãs), seria uma visita, ficávamos apavoradas. A gente corria, se escondia, mas éramos pegas. Ficávamos com muita raiva da injeção, mas, talvez, mais ainda com o escondido dos avós. Era horrível saber que éramos facilmente "enganáveis".

O que não podíamos saber era vivido como horror, sem saber.

À procura de palavras para dizer o indizível. Vou a uma ópera apresentada em Nova York e sou tocada por aquilo que transmite justamente o horror, também de um autor à procura desse dizer testemunha, o exilado polonês, judeu, Mieczyslaw Weinberg. A ópera é um surpreendente relato dos horrores da Segunda Guerra Mundial e do domínio inabalável que as lembranças e os tormentos daquela época podem ter até hoje. The Passenger, ${ }^{1}$ baseada no romance semiautobiográfico Pasazerkaby, da sobrevivente de Auschwitz Zofia Posmysz, é sobre o encontro de duas mulheres - uma ex-guarda nazista de Auschwitz e uma prisioneira, ex-reclusa do quartel feminino - a bordo de um transatlântico - , um olhar que as leva para uma viagem ao passado, a suas memórias dos horrores do Holocausto, colocando o agressor contra a vítima, numa batalha moral entre culpa e negação, retribuição e absolvição.

1 The Passenger - ópera em dois atos. Compositor: Mieczyslaw Weinberg. Libretista: Alexander Medvedev. Ano: 1968. Estreia: Moscou, 2006. Adaptação do livro Pasazerkaby (Zofia Posmysz). Idiomas: inglês, alemão, russo e polaco. 
O diretor, David Pountney, organiza brilhantemente esse trabalho, levando o público de uma viagem no elegante convés do transatlântico de luxo a outra cena, miséria de um campo de extermínio nazista, onde a crueldade, o desespero e a coragem inexprimível são evidentes em igual medida.

Mas, ao ver as moças na segunda cena com pijamas listrados, prisioneiras e carecas, logo senti um arrepio muito forte, insight, posso chamar assim, ao associar as carecas, cabeças raspadas, à careca - nome do câncer, por excelência -, e o horror da mulher prisioneira ao silêncio da minha avó. Foi muito impressionante essa experiência, chorei muito.

Eram uns avós que viveram a guerra e não puderam contar a história, pois lhes era muito pesado lembrar, história que ficou recusada. Assim, o melhor que puderam passar era "melhor não saber"; a cena contada por minha avó era dela escondida na casa de estranhos que a acolheram, onde, sentada ao piano, enquanto tocava, notava a visita de um coronel do exército, via a sombra e o barulho de suas botas se aproximando e tinha muito medo de ser descoberta. Vivia escondida como católica nessa família, depois que foi impelida pelo pai a sair de casa para ser salva. Diante da pisada forte do coronel e do horror de ser encontrada, joga fora as últimas fotografias da família.

Uma marca, um arrepio, um afeto, falava de lalíngua, como traduzir um corpo afetado pela língua, um para além das palavras que falava sobre mim... Isso queria transmitir. Testemunhar seria achar as palavras (as anotações) para aquilo que não para de não se escrever, palavras para não sucumbir ao abismo?

Pego emprestadas as palavras de Soler, no livro El fin y las finalidades del análisis:

Os afetos enigmáticos evocados no final de Mais, ainda revelam e manifestam a presença dos afetos de lalíngua que sobrepassam o sujeito, que vão mais longe do que se pode formular sobre eles, e que permanecem não sabidos. (Soler, 2013, p. 59, tradução nossa)

Precisei de muitas voltas e algum tempo para me "tocar" disso, até que, num momento, um novo nome, a descolada, dava as caras, cara nova.

\section{Hoje foi a despedida}

Fiquei o fim de semana com o rosto dela, da analista, colado na cabeça, tentando saber que cara era aquela: "O que é isso, Adriana?" - a voz repetia. Tentei, muitas vezes, interpretar o que ela estava dizendo ou responder ao que me perguntava; tudo caía, não colava. Estava, nesse momento, trabalhando num texto, voltando a seminários antigos, revendo anotações e achando alguns escritos da análise pelos livros. Vou para a sessão incomodada com essa aparição e contando o que me havia acontecido, assim como o meu caminho de escrita 
naquele momento, e algumas coincidências. Até que parei, me toquei e disse: "Vi a sua cara!". Era só isso, o rosto dela. Sem interpretações. Elas caíam. Aparecia outro, dissolvia a transferência.

Percebi também que não falava disso com todas as letras, como se ela fosse me mandar embora. Ficou essa marca de não querer largar, mas a percepção de que o que eu trazia caía, esvaziava e ficava evidente.

O fim estava na cara.

Ela diz: "Que virada!".

Eu digo: "Pois é", e me levanto.

Ela olha para mim e diz: "É isso?".

Emocionada, digo: "É isso!".

É isso, só isso, que reverberou por um tempo...

Um suspiro... Já lá fora, percebo o "feliz acaso", "o sujeito é feliz dever tudo ao acaso” (Lacan, 1973, p. 525). Essa deve ser a descoberta da satisfação.

\section{Referências bibliográficas}

Assis, M. (2008). Contos (p. 339). Belo Horizonte: Itatiaia. (Grandes obras da cultura universal).

Lacan, J. (1973). Televisão. In J. Lacan. Outros escritos (V. Ribeiro, Trad.) (pp. 508-543). Rio de Janeiro: Jorge Zahar.

Lacan, J. (1998). O seminário, livro XI: os quatros conceitos fundamentais da psicanálise. (M. D. Magno, Trad.). Rio de Janeiro: Jorge Zahar. (Trabalho original publicado em 1964)

Lacan, J. (2003). Proposição de 9 de outubro de 1967. In J. Lacan. Outros escritos (V. Ribeiro, Trad.) (pp. 248-264). Rio de Janeiro: Jorge Zahar. (Trabalho original publicado em 1967)

Lacan, J. (2010). O seminário, livro XX: encore. (Versão brasileira fora do comércio). (Trabalho original publicado em 1972-1973)

Soler, C. (2005). O que Lacan dizia das mulheres (V. Ribeiro, Trad.). Rio de Janeiro: Jorge Zahar.

Soler, C. (2013). El fin y las finalidades del análisis. Buenos Aires: Letra Viva.

Recebido: 29/10/2019

Aprovado: 31/10/2019 